\title{
The influence of damping layer on the modal of water-lubricated rubber bearing
}

\author{
Li HUANG ${ }^{a}$, Yong JIN and Zheng Lin LIU
}

School of Power and Energy, Wuhan University of Technology, Wuhan 430063, China

\begin{abstract}
In order to find out the influence of damping layer on water-lubricated rubber bearing, element finite modal analysis in Workbench is used and three bearings with different damping layers are studied as well as an ordinary bearing without damping layer. The results show that the damping bearings have lower modal frequencies than the ordinary bearing, and the damping layer length and thickness can influence the deformation distribution of modal shape.
\end{abstract}

\section{Introduction}

Structural vibration can bring noise, reduce the life of components and even lead to failure of components in the field of ship, aviation, machinery and so on, thus always being the research hot spot. Damping layer is made of polymer material, and there is a phase difference between stress and strain in damping layer under the effect of vibration. This difference has to overcome great resistance which can reduce vibration of components by dissipating the vibration energy[1]. So, damping layer has been widely used to reduce structural vibration and has made distinct effect. For example, by applying it into the design of bellows, high-damping unreinforced U-shaped vibration reducing bellows was developed[2]; In the application of flat plate structure, damping layer was studied by scholars with variables to optimize beams with damping sandwich[3]. In these fields, the damping layer has made a contribution to the vibration reduction and noise reduction.

In recent years, water lubricated rubber bearings have been widely used in underwater vehicle[4,5]. Many scholars have used modal analysis to study the characteristics of water lubricated rubber bearings. Like Jin Yong[6,7] used simulation and experimental analysis to study the influence factors of modal properties of water lubricated rubber bearings, and found that the main influence of lower order modes is structure and material of liner and the main influence of higher order modes is structure and material of bush. Modal analysis can get the natural frequency and the relative deformation of the bearing under different natural frequencies, which has theoretical meanings and practical application values to the optimization of bearing structure and fault diagnosis.

In view of the good vibration performance of damping layer in other structure and the demand for reducing the vibration of water lubricated rubber bearings, this paper use finite element modal analysis to study the modal propertiesof water lubricated rubber bearings in Workbench. Here, influence of different damping layers on modal frequency and modal shape of bearings are taken into account.

\footnotetext{
a Li Huang :415540616@qq.com,Wuhan University of Technology
} 


\section{Modal}

Damping layer is added to the cylindrical surface of ordinary bearing, with an outer bush. The arrangement of damping layer in the water lubricated rubber bearing is shown in Figure 1. Three-dimension geometry modelsare built based on the water lubricated rubber bearing in Workbench. Bearing $\mathrm{A}$ is ordinary bearing, and bearing
B2 and B3 are changed base on that of B3, to study the influence of different damping layers on the bearings.Material parameters of bearings are listed in table 1. Geometric parameters of bearings are listed in table 2. All the damping layers are symmetric arrangement. The difference between damping bearing B1 and any other damping layer bearing is listed in table 3.

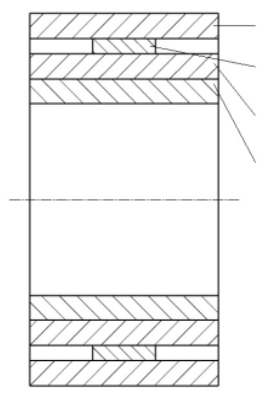

Outer bush Damping layer Inner bush Rubber liner

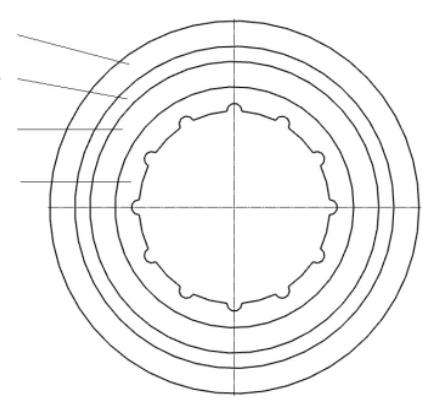

Fig.1 Profile of damping bearing

B1, B2, and B3 are damping bearings. The parameters of

Table1 Material parameters of bearings

\begin{tabular}{ccccc}
\hline Name & Material & Poisson ratio & Density/ $(\mathrm{kg} / \mathrm{m} 3)$ & Young's modulus/ $(\mathrm{MPa})$ \\
\hline Rubber liner & Nitrile rubber & 0.47 & 1240 & 7.08 \\
Inner/outer bush & Q235 & 0.288 & 7860 & $2.12 \mathrm{e} 5$ \\
Damping layer & Nitrile rubber & 0.47 & 1080 & 4.44 \\
\hline
\end{tabular}

Table2 Geometric parameters of bearings

\begin{tabular}{|c|c|c|c|c|c|c|c|}
\hline Type & $\begin{array}{l}\text { Internal } \\
\text { diameter }\end{array}$ & $\begin{array}{l}\text { Thickness } \\
\text { of liner }\end{array}$ & $\begin{array}{c}\text { Thickness of } \\
\text { inner bush }\end{array}$ & $\begin{array}{l}\text { Thickness of } \\
\text { damping layer }\end{array}$ & $\begin{array}{c}\text { Length of } \\
\text { damping layer }\end{array}$ & $\begin{array}{c}\text { Thickness of } \\
\text { outer bush }\end{array}$ & $\begin{array}{c}\text { Length of } \\
\text { bearing }\end{array}$ \\
\hline $\begin{array}{l}\text { Ordinary } \\
\text { bearing A }\end{array}$ & 150 & 20 & 20 & 1 & 1 & 1 & 150 \\
\hline $\begin{array}{l}\text { Damping } \\
\text { bearingB1 }\end{array}$ & 150 & 20 & 20 & 12 & 50 & 20 & 150 \\
\hline
\end{tabular}

Table3 The difference between damping bearing B1 and any other damping layer bearing

\begin{tabular}{ccccc}
\hline Type & Particular & $\begin{array}{c}\text { Thickness of } \\
\text { damping layer/mm }\end{array}$ & $\begin{array}{c}\text { Length of damping } \\
\text { layer } / \mathrm{mm}\end{array}$ & $\begin{array}{c}\text { Young's modulus of } \\
\text { damping layer/MPa }\end{array}$ \\
\hline Damping bearing B1 & $\begin{array}{c}\text { Reference } \\
\text { Change damping } \\
\text { layer thickness } \\
\text { Damping bearing B2 }\end{array}$ & 12 & 50 & 4.44 \\
Damping bearing B3 & $\begin{array}{c}\text { Change damping } \\
\text { layer length }\end{array}$ & 14 & 50 & 4.44 \\
\hline
\end{tabular}




\section{Modal analysis}

\subsection{Finite element modal analysis}

Modal analysis is mainly used to identify the vibrating characteristic of the framework.It has important significance on the dynamic response of the system, the generation and transmission of the dynamic load and the form of the system vibration, also it is the base for all other type of dynamics analysis. The Lanczos Block method is used to calculate the constraint mode of water lubricated bearings. According to the actual operation condition, the outer cylindrical surface of the outer bushing is fully restrained. Extract the modes of the first 20 orders of the bearings.

\subsection{Modal frequency}

According to the calculation modal frequencies of different bearings, we could draw Figure 2 and obtain the following results:

(1)The damping layer reduces natural frequencies of the bearing. It has a strong effect on the lower modes(sixth-order below) but a small effect on the highermodes(sixth-order above).

(2) The ordinary bearing has a larger arrangement of natural frequencies than the damping bearings.

(3) Influence of the damping layer length: natural

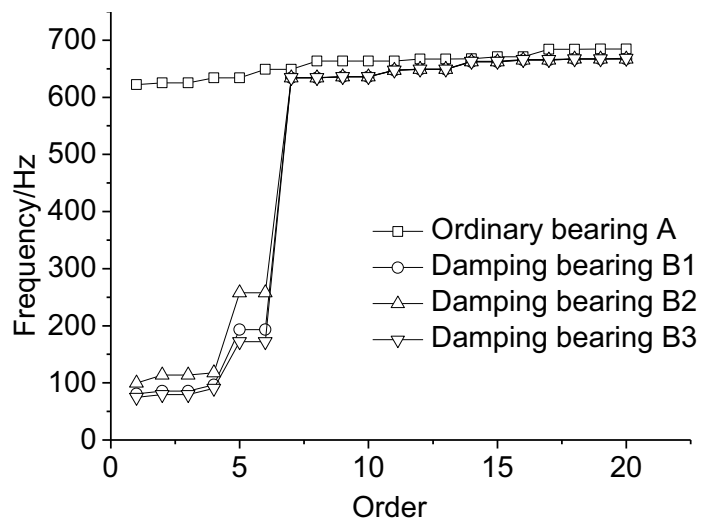

Fig.2 Influence of damping layer on modal frequency

frequencies of the damping layer increase with the increase of damping layer length, and the influence is significant on fifth and sixth order frequencies, and there is little influence on natural frequencies of sixth-order above.

(4) Influence of the damping layer thickness: natural frequencies of the bearing decrease with the increase of damping layer thickness, and the influence is significant on fifth and sixth order frequencies, and there is little influence on natural frequencies of sixth order above

\subsection{Modal shape}

Analysis different modal shapes of bearings with their corresponding modal frequencies, we could obtain the following results:

(1) The ordinary bearing has many orthogonal modes, like the first-order mode and the third-order mode, and the forth-order mode and the fifth-order mode, because there are many multiple roots in the modal solving equation.

(2) The damping bearings also has a lot of orthogonal modes, and its orthogonal modes correspond to the same order as the ordinary bearing.

(3) When two of the bearings have a close natural frequency, their corresponding modal shapes are similar. For example, as shown in Figure 3, around 634Hz, these

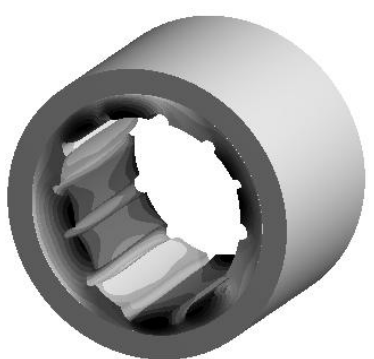

(a) Fourth-order modal shape of the ordinary bearing $(634.28 \mathrm{~Hz})$

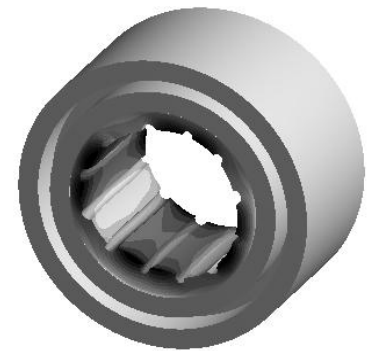

(c) Seventh-order modal shape of the damping bearing B2 $(634.06 \mathrm{~Hz})$

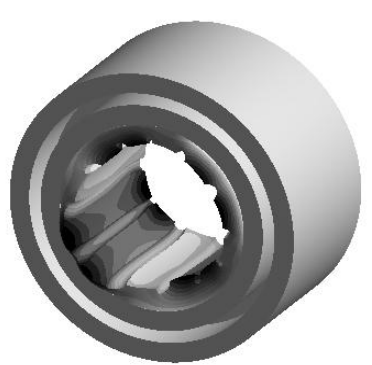

(b) Seventh-order modal shape of the damping bearing B1 $(634.07 \mathrm{~Hz})$

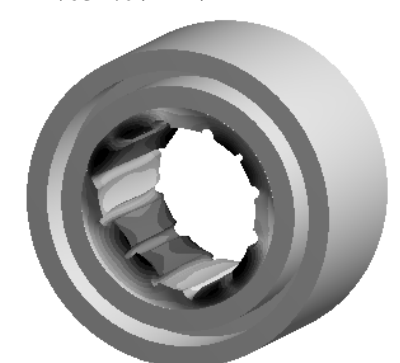

(d) eighth-order modal shape of the damping bearing $\mathrm{B} 3$

$(634.71 \mathrm{~Hz})$
Fig. 3 Modal shapes of bearings relevant to close frequency

four bearings have a close natural frequency, so they have 
a similar modal shape. We could find from every bearing in Figure 3 that the vibration is happened in the inner liner, and the respective maximum deformation occurs at the end of two adjacent strips, and between two couples of maximum deformation strips there is one strip of very small deformation.

(4) Compared with the ordinary bearing, the damping bearing has a larger deformation area. Figure 4 shows lower-order modal shapes of damping bearing B1. From Figure 4 we could find that the lower-order deformation of damping bearing $\mathrm{B} 1$ relates to its inner liner, inner bush and damping layer. However, the deformation of the ordinary bearing of the same order relates only to its inner bush, as shown in Figure 3(a).

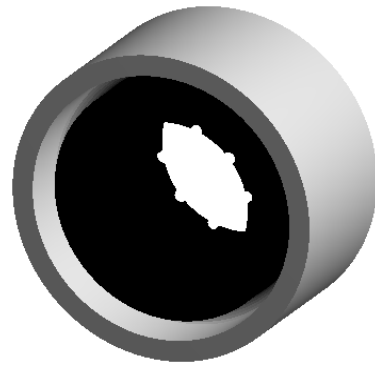

(a) First-order modal shape of the damping bearing B1 $(80.943 \mathrm{~Hz})$

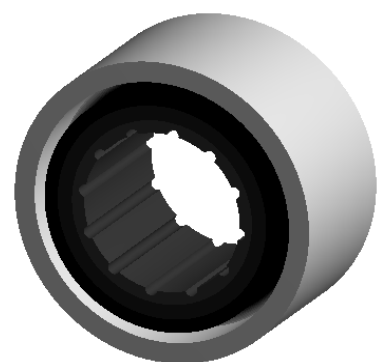

(b) Fourth-order modal shape of the damping bearing $\mathrm{B} 1(96.541 \mathrm{~Hz})$

Fig.4 Modal shape of damping bearing B1

(5) The influence of damping layer length: compare bearing $\mathrm{B} 1$ with $\mathrm{B} 2$, we could find that the increase of damping layer length affects the fifth-order shape and sixth-order shape more than others. Figure 5 and Figure 6 show the modal shapes of fifth-order and sixth-order of bearing B1 and B2. These two bearings have different areas of deformation and the maximum deformation relates to a larger area in B1 than in B2.

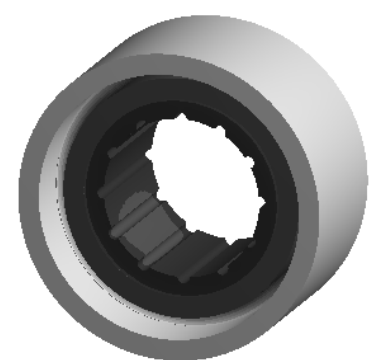

(a) Fifth-order modal shape of the damping bearing B1 (193.31Hz)

Fig 5 Fifth-order and sixthdamping bearing B1

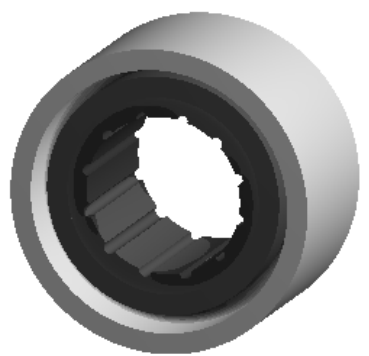

(a) Fifth-order modal shape of the damping bearing B2 $(257.79 \mathrm{~Hz})$

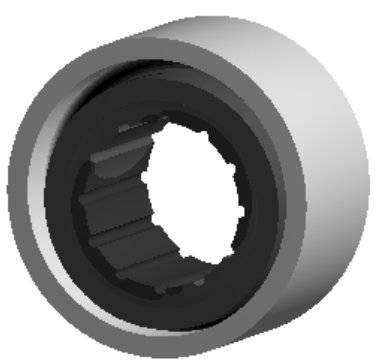

(b) Sixth-order modal shape of the damping bearing B2 $(257.79 \mathrm{~Hz})$
Fig.6 Fifth-order and sixth-order modal shape of the damping bearing $\mathrm{B} 2$

(6) The influence of damping layer thickness: compare bearing B1 with $\mathrm{B} 3$, we could find that the increase of damping layer length affects the fifth-order shape and sixth-order shape more than others. Figure 7 shows the modal shapes of seventh-order of bearing $B 1$ and B3. We can see that the inner bush of bearing B3 has a similar deformation with its inner liner, which is larger than that of bearing B1.

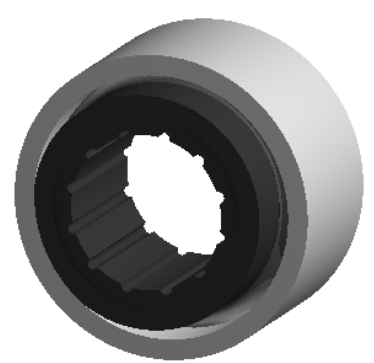

(a) Fifth-order modal shape of the damping bearing B3 $(172.18 \mathrm{~Hz})$

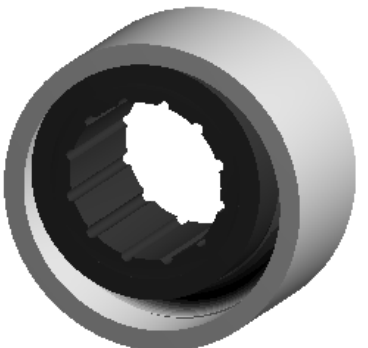

(b) Sixnth-order modal shape of the damping bearing B3 $(172.18 \mathrm{~Hz})$
Fig.7 Fifth-order and sixth-order modal shape of the damping bearing $\mathrm{B} 3$

\section{Conclusions}

The main conclusions are as follows:

(1) The damping bearing has lower natural frequencies than the ordinary bearing. When it comes to lower modes(six order below), the difference is significant, and the deformation area of damping bearing is larger than that of ordinary bearing.

(2) The damping layer length has a large influence on modal frequency, especially on fifth-order and sixth-order modal frequency, while the damping layer thickness has a small influence. 
(3) The damping layer length and the damping layer thickness have larger effect on fifth-order and sixth-order shape than on other orders, and they can influence the distribution of relative deformation.

\section{References}

1. Huang Zhicheng, Qin Zhaoye, Chu Fulei. J.Vibra. Shock,33,105 (2014)

2. ZhongYuping, Chen Tongbiao. Pressure Vessel Technology,22, 21 (2005)
3. JinqiangLi, Yoshihiro Narita.,J. V. C.,2. 20 (2014)

4. D. de Kraker, R. A. J. vanOstayen, D. J.Rixen,TribologyInternational,403 (2006)

5. Zhou Huanhuan, Yu Qiang, Li Tianyun, Ship Engineering, 04.25 (2015)

6. Jin Yong, TianYuzhong, Liu Zhenglin, Lubrication Engineering, 09.10 (2011)

7. Jin Yong, TianYuzhong, Liu Zhenglin, Noise Vibra.Contrl. 32.1 (2012) 